\title{
Hygroscopicity of organic compounds as a function of organic functionality, water solubility, molecular weight and oxidation level
}

Shuang Han $^{1,2}$, Juan Hong ${ }^{1,2}$, Qingwei Luo ${ }^{1,2}$, Hanbing $\mathrm{Xu}^{3}$, Haobo Tan ${ }^{4,5}$, Qiaoqiao Wang ${ }^{1,2}$, Jiangchuan Tao ${ }^{1,2}$, Yaqing Zhou ${ }^{1,2}$, Long Peng ${ }^{1,2}$, Yao He ${ }^{1,2}$, Jingnan Shi ${ }^{1,2}$, Nan Ma ${ }^{1,2}$, Yafang Cheng ${ }^{6,7}$ 5 and Hang $\mathrm{Su}^{6,7}$

${ }^{1}$ Institute for Environmental and Climate Research, Jinan University, Guangzhou, Guangdong 511443, China

${ }^{2}$ Guangdong-Hongkong-Macau Joint Laboratory of Collaborative Innovation for Environmental Quality, Guangzhou, China

${ }^{3}$ Experimental Teaching Center, Sun Yat-Sen University, Guangzhou 510275, China

${ }^{4}$ Institute of Tropical and Marine Meteorology/Guangdong Provincial Key Laboratory of Regional Numerical Weather

10 Prediction, CMA, Guangzhou 510640, China

${ }^{5}$ Foshan Meteorological Service of Guangdong, Foshan 528010, China

${ }^{6}$ Minerva Research Group, Max Planck Institute for Chemistry, Mainz

${ }^{7}$ Multiphase Chemistry Department, Max Planck Institute for Chemistry, Mainz 55128, Germany

Correspondence: Juan Hong (juanhong0108@jnu.edu.cn) and Nan Ma (nan.ma@jnu.edu.cn)

15 Abstract. Hygroscopic properties of 23 organics including carboxylic acids, amino acids, sugars and alcohols were characterized using a Hygroscopicity Tandem Differential Mobility Analyzer (HTDMA). We show that hygroscopicity of organics varies widely with different functional groups and organics with additional functional groups are more hygroscopic. However, some compounds sharing the same molecular formula or functionality show quite different hygroscopicity, demonstrating that other physico-chemical properties may contribute to their hygroscopicity as well. If the organics are fully

20 dissolved in water (solubility $>7 \times 10^{-1} \mathrm{~g} / \mathrm{ml}$ ), we found that their hygroscopicity is mainly controlled by their molecular weight. For the organics that are not fully dissolved in water (slightly soluble: $5 \times 10^{-4} \mathrm{~g} / \mathrm{ml}<$ solubility $<7 \times 10^{-1} \mathrm{~g} / \mathrm{ml}$ ), we observed that some of them show no obvious water uptake, which probably due to that they may not deliquesce under our studied conditions up to $90 \% \mathrm{RH}$. The other type of slightly soluble organics is moderate hygroscopic and the larger their solubility the higher their hygroscopicity. Moreover, the hygroscopicity of organics generally increased with O:C ratios, although this

25 relationship is not linear. Hygroscopicity of organic compounds were also predicted by two thermodynamic models using the Extended Aerosol Inorganics Model (E-AIM) and UManSysProp. Both models do not consider phase transition and intermolecular interactions in the simulations and show poor representation of the hygroscopicity for most of the organics.

\section{Introduction}

Atmospheric aerosol particles consist of numerous organic species with both anthropogenic and biogenic origins (Zhang et al.,

30 2007; Zhang et al., 2015; Wang et al., 2018; Jimenez et al., 2009). These organic species often contribute a significant fraction to the mass of sub-micrometer aerosols, and have vital effects on air-quality and climate (Mcfiggans et al., 2006; Randall et al., 2007; Zheng et al., 2015). To obtain a systematic understanding of their effects, it is necessary to acquire correct 
information on the chemical composition and physico-chemical properties of these organics (Wang et al., 2015). Hygroscopicity is one of the most important physico-chemical properties, which describes the ability of particles to take up water and grow in size under sub- and supersaturated conditions (Su et al., 2010; Hong et al., 2018; Tang et al., 2019; Cheng et al., 2008).

Given the big number of organic species in atmospheric aerosols, the determination of their hygroscopicity is quite experimentally difficult. Current models normally use aggregate quantities, such as the atomic oxygen-to-carbon (O:C) ratio or the average oxidation state of organics to simply parameterize the hygroscopicity of organic species in ambient aerosols.

40 However, recent studies show that the hygroscopicity of organic aerosols cannot be fully explained by their oxidation level and the empirical relationship between hygroscopicity and O:C might not be linear (Lambe et al., 2011; Kuwata et al., 2013; Rickards et al., 2013; Marsh et al., 2017). This suggests that other physico-chemical properties such as molecular functionality, molecular weight and water solubility of organics may also influence their hygroscopicity.

Due to this challenge, prediction of the hygroscopicity of organic compounds sometimes rely on thermodynamic models which explicitly includes these properties, for instance molecular functionality, molecular weight, into simulations. These thermodynamic models, including the Aerosol Inorganic-Organic Mixtures Functional groups Activity Coefficients (AIOMFAC) (Zuend et al., 2008; Zuend et al., 2011), the Extended Aerosol Inorganic Model (E-AIM) and the UManSysProp (Topping et al., 2016; Clegg et al., 1998) using group contribution methods to calculate water activity for organic species of atmospheric relevance. However, involving these thermodynamic simulations in transport or climate models to predict the

50 hygroscopicity for such a large number of organic compounds in ambient aerosols is computationally expensive. Moreover, these models, based on parameterizations from experimental data are semi-empirical and cannot capture the non-ideality of the solutions accurately, especially under very dry conditions (Suda and Petters, 2013). Particularly, when it comes to the mixtures with the presence of inorganic species, these models may perform even worse without the consideration of the ionneutral interactions (Lei et al., 2014; Jing et al., 2016; Luo et al., 2020).

55 These limitations in models demonstrate an imperfect understanding of the interactions between organic species and water molecular. In order to better understand their interactions and further improve the parameterization in models, there is an intrinsic necessity to quantify organic hygroscopicity through laboratory measurements. Suda et al. (2014) examined the hygroscopicity of a few organic compounds with an extra or more functional groups to similar molecules. They found that the compounds with hydroxyl or carboxyl groups are the most hygroscopic, while the ones with nitrate or methylene are the least. Marsh et al. (2017) collected hygroscopicity data for 23 organic compounds to compare with thermodynamic predictions and discussed that the hygroscopicity of organic compounds are poorly represented by models with increasing branching and chain length of the molecules. Although there is some experimental data of the hygroscopicity of organics with high atmospheric abundance and relevance (Peng et al., 2001; Prenni et al., 2007; Chan et al., 2008; Lambe et al., 2011; Kuwata et al., 2013; Marsh et al., 2017; Lei et al., 2018), those previous studies mostly focus on either a quite small number of organics or one or two perspectives influencing the hygroscopicity. A general picture in understanding the observed hygroscopicity among 
different organic species remains unclear. Hence, a systematic matrix of experimentally determined hygroscopicity data synthesizing a large suite of organics is essentially needed.

In the present study, we investigated the hygroscopicity of 23 atmospheric relevant organic species by a self-assembled Hygroscopicity Tandem Differential Mobility Analyzer (HTDMA). In particular, we systematically evaluated the role of molecular complexity including both molecular structures and relevant physico-chemical properties in classifying aerosol hygroscopicity. In addition, predictions from two thermodynamic models are compared against the experimental data.

\section{Measurements}

Submicron aerosol particles were generated by nebulizing the aqueous solutions $\left(0.1 \mathrm{~g} \mathrm{~L}^{-1}\right)$ of each compound using a constant output atomizer (TSI, 3076). The solutions were prepared by ultrapure water (Millipore, resistivity $\geq 18.2 \mathrm{M} \Omega$ ). The physiochemical properties of the studied 23 compounds are summarized in Table 1.

After particle generation, the particles were introduced into a self-assembled HTDMA system where their hygroscopic growth factor $(\mathrm{GF}(\mathrm{RH}))$ can be measured. $\mathrm{GF}(\mathrm{RH})$ is defined as Eq. (1):

$G F\left(R H, D_{0}\right)=\frac{D(R H)}{D_{0}}$,

where $\mathrm{D}(\mathrm{RH})$ and $D_{0}$ are the equilibrium mobility diameter of the particles at a given $\mathrm{RH}$ and dry condition $(<10 \% \mathrm{RH})$, respectively. Figure S1 shows the schematic of the HTDMA system. The detailed principle of the HTDMA system can be found in Tan et al. (2013) Residence time for humidication of the generated aerosols is around 2.7 seconds. Calibration of the system was performed using ammonium sulfate (AS) and the results shown in Fig. S2 display that the measured hygroscopic behaviour of AS agreed well with previous studies with the deliquescence RH around $78 \%$.

According to $\kappa$-Köhler theory, we converted the measured hygroscopic growth factor to the single hygroscopicity parameter

$85 \kappa($ Eq. 2,3) to facilitate the comparison of the hygroscopic properties among different compounds (Petters and Kreidenweis, 2007):

$\kappa=\frac{\left(G F^{3}-1\right)\left(1-\frac{R H}{K e}\right) K e}{R H}$,

$K e=\exp \left(\frac{4 \sigma_{s o l M_{W}}}{R T \rho_{w} D(R H)}\right)$,

where $M_{w}$ and $\rho_{w}$ are the molar mass and the density of pure water at temperature T, respectively; $\sigma_{s o l}$ is the solution droplet surface tension, which was assumed to be the surface tension of water $\left(0.072 \mathrm{~J} \mathrm{~m}^{-2}\right)$ and $\mathrm{R}$ is the ideal gas constant. 


\section{Modeling}

The E-AIM and UManSysProp are applied in this study to simulate the hygroscopic behaviour of the 23 organic species. EAIM is a thermodynamic model for calculating gas, liquid and solid partitioning in aerosol systems (Clegg et al., 1998; Wexler, 2002), while UManSysProp (University of Manchester System Properties) is an online model to predict the hygroscopic growth factors of organic and inorganic species. Both models use the group contribution method of Universal quasi-chemical Functional group Activity Coefficients (UNIFAC) to characterize the subgroups of organic molecules and calculate activity coefficients based on the contributions from these subgroups (Fredenslund et al., 1975; Hansen et al., 1991). The detailed input setting and calculations for E-AIM and UManSysProp are given in Supplement.

\section{Results and discussion}

\section{4.1 Hygroscopicity of individual organics}

In this section, we summarized the measured and predicted hygroscopic properties of the 23 organic species, which are classified into three groups based on their functionality. Particles at the dry size of $200 \mathrm{~nm}$ were selected for analysis.

\subsubsection{Carboxylic acids}

Carboxylic acids are the most abundant water-soluble components identified in atmospheric aerosols (Chebbi and Carlier,

105 1996; Mochida et al., 2003; Kundu et al., 2010). Hygroscopic properties of straight-chain dicarboxylic acids have been extensively investigated in previous studies (Chan et al., 2008; Rickards et al., 2013; Kuwata et al., 2013), however, experimental data for dicarboxylic acids with additional substitutions and tricarboxylic acids are limited. To achieve a comprehensive overview of the hygroscopicity of carboxylic acids, we extended our hygroscopic measurements for dicarboxylic acids with substitutions and tri-carboxylic acid besides those commonly used straight-chain dicarboxylic acids.

110 Figure 1 shows the measured and predicted humidograms of straight-chain dicarboxylic acids (Fig. 1a), dicarboxylic acids with substitutions (Fig. 1b) and tricarboxylic acids (Fig. 1c), respectively. Need to note that the E-AIM model cannot simulate the dissociation of tricarboxylic acids in aqueous phase. Hence, the hygroscopic growth of tricarboxylic acids was only modeled with the UManSysProp.

Among the studied straight-chain dicarboxylic acid, only Malonic acid showed continuous hygroscopic growth with increasing

115 RH and the measured GF at $90 \%$ RH was 1.47, which agrees well with previous studies (Peng et al., 2001; Prenni et al., 2001; Wise et al., 2003). Figure 1a also shows that the hygroscopic behaviour of Malonic acid was well represented by the E-AIM but overestimated by the UManSysProp. The other straight-chain dicarboxylic acids (i.e., Succinic, Adipic, Pimelic, Suberic and Azelaic acids) did not show any water uptake at $\mathrm{RH}<=90 \%$, which was not captured by the UManSysProp. Assuming a solid state of these dicarboxylic acids, the E-AIM was capable to predict their non-hygroscopicity. Similar results were also found in previous studies (Prenni et al., 2001; Kuwata et al., 2013; Rickards et al., 2013; Jing et al., 2016) and Chan et al. 
(2008) explained that these dicarboxylic acids have quite low-solubility in water and once they crystallized, they would not deliquesce even under high RH conditions (e.g., RH $<90 \%$ ). Moreover, we found that the measured GFs of these dicarboxylic acids were less than 1 , which could be attributed to the adsorption of a small amount of water at the particle surface, leading to the rearrangements of the microstructure and compaction of the particle (Mikhailov et al., 2004; Mikhailov et al., 2009).

The humidograms of the three dicarboxylic acids with substitutions (i.e., double bond or hydroxy group) are illustrated in Fig. 1b. The continuous water uptake indicates that these particles may be at liquid state under dry conditions. We observed a small leap of the GFs from $80 \%$ to $85 \% \mathrm{RH}$, implying that these particles were only partially deliquesced and further dissolution occurred at elevated RHs Mikhailov et al. (2009) provided a plausible explanation that a gel-like structure in the aqueous droplets may form at low water activities but collapse when the volume fraction of water exceeds a certain amount, which leads to a prompt increase in GF at relative higher RHs. However, without a proper estimate of the phase state of particles, both models did not capture this gradual phase transition accurately, suggesting that current models are quite simplified with insufficient input data and additional measurements improving the parameterization in models are needed.

Gradual phase transition was also observed for Citric acid (Fig. 1c), while the other two tri-carboxylic acids (i.e., Aconitic acid and Tricarboxylic acid) did not show visible phase change with continuous hygroscopic growth over the studied RH range.

135 Predictions from the UManSysProp mostly agreed well with the experimental data, especially above $80 \%$ RH, with some slight underestimations at lower RHs.

\subsubsection{Amino acids}

Figure 2 shows the measured humidograms of the 5 amino acids and their corresponding thermodynamic predictions. The continuous water uptake was observed for particles of Serine, Glutamine and Aspartic acid, indicating that there was no phase transition occurred during the hydration cycle. Alanine acid particles showed no water uptake with GFs less than unity at RH $<90 \%$, which has also been reported in previous works (Chan et al., 2005; Darr et al., 2018). For Glycine, we observed a continuous shrink in wet particle size from $30 \% \mathrm{RH}$ to $80 \% \mathrm{RH}$, and above $80 \% \mathrm{RH}$ the GFs increased slightly. Previous literatures have reported that Glycine particles started to absorb water above $60 \%$ RH (Marsh et al., 2017; Chan et al., 2005; Darr et al., 2018). prior to deliquescence due to capillary effect, which could also be the potential reason for the shrinkage in

145 particle size of Glycine during hydration as a result of the microstructural rearrangement of particles upon humidification. Moreover, Marsh et al. (2017) and Darr et al. (2018) observed that water content of glycine aerosols began to increase continuously above $60 \% \mathrm{RH}$. Though, the droplet size shrink or grow slightly under different RH conditions in our observations, the mass fraction of water was always increasing, which agrees well with previous results. Actually, it can not to be defined that deliquescence of Glycine particles occurred at $\mathrm{RH}<90 \%$ under our experimental conditions.

150 Predictions of Serine, Glutamine, Alanine and Aspartic acid agrees generally better with measurements than that of Glycine, although overestimation was observed for all the 5 amino acids. Luo et al. (2020) discussed that the UNIFAC ignored the intramolecular interactions between amine and carboxylic groups in both models, resulting in the observed difference in the measured and predicted GFs. 


\subsubsection{Sugars and Sugar alcohols}

155 Two-stage-like gradual hygroscopic growths were also observed for particles of Fructose, Mannose, Sucrose, Xylitol and LArabitol, shown in Fig. 3. The experimental results of those sugars and sugar alcohols are consistent with previous literature data (Chan et al., 2008; Estillore et al., 2017). Compared to other sugars and sugar alcohols, Sucrose is slightly less hygroscopic with a mild downward trend in GFs at low RHs and the GF at $85 \%$ RH was around 1.21, which is similar with the results of Estillore et al. (2017). Moreover, Mannitol is the least hygroscopic or even hydrophobic with GF less than unity at $90 \%$ RH, which also agrees with previous literatures (Martău et al., 2020; Ohrem et al., 2014).

Similarly, phase transition or microstructural rearrangements of particles was not included in the models. Thus, these sugars and sugar alcohols were generally less hygroscopic than the values predicted by the E-AIM (except L-Arabitol) under low RH conditions. On the other hand, at elevated RHs, whereas particles are fully dissolved, the E-AIM is capable to well represent their hygroscopic properties as well as for Mannitol if a solid state was assumed in the simulations and the microstructural rearrangement of particles was ignored.

\subsection{Relating the hygroscopicity of organic compounds to their physico-chemical properties}

In this section, we explore the effects from different physico-chemical properties such as molecular functionality, water solubility and organic oxidation level that potentially contribute to the observed hygroscopicity $\kappa$. Need to note that the hygroscopicity parameter $\kappa$ discussed in this section was converted by using growth factor data measured at $90 \% \mathrm{RH}$ (except for Sucrose at $85 \% \mathrm{RH})$.

\subsection{1 к vs. organic functionality}

Figure 4a shows the measured hygroscopicity of the 23 organics as a function of carbon number. The functional groups with their corresponding numbers are indicated with colors and symbols. In order to facilitate the comparison of the compounds with the same carbons, the carbons with only one compound are not illustrated. For the studied organic compounds with the same carbon number, the hygroscopicity was increased by the addition of extra functional groups to the carbon backbone. For instance, Maleic, Malic, Tartaric and Aspartic acid with extra functional groups (e.g., C=C, - $\mathrm{OH}$ and $-\mathrm{NH} 2$ ) with respect to Succinic acid with only two -COOHs are more hygroscopic. For C7 compounds, an additional carboxylic acid group to the carbon backbone leads to an elevated hygroscopicity from Pimelic to Tricarboxylic acid. Moreover, organic compounds with the same carbon numbers but different molecular functionality presented quite distinct hygroscopicity. For example, for C3 compounds, if replacing the $-\mathrm{CH} 3$ with an $-\mathrm{OH}$ or replacing the $-\mathrm{OH}$ group by an $-\mathrm{COOH}$ in their parental molecules, the hygroscopicity was significantly increased. Taking another example from $\mathrm{C} 4$ compounds, the organics with a hydroxyl group $(-\mathrm{OH})$ instead of an $-\mathrm{NH} 2$ or with a double bond $(\mathrm{C}=\mathrm{C})$ instead of the hydroxyl group in their carbon backbones were more hygroscopic. Similar difference in hygroscopicity was also observed between Aconitic acid (C6) with a $\mathrm{C}=\mathrm{C}$ and Citric acid (C6) with a $(-\mathrm{OH})$. In general, the $\kappa$ increased with the functionality in the following order: $(-\mathrm{CH} 3$ or $-\mathrm{NH} 2)<(-\mathrm{OH})<(-$ 
$185 \mathrm{COOH}$ or $\mathrm{C}=\mathrm{C}$ or $\mathrm{C}=\mathrm{O}$ ). Suda et al. (2012) and Chen et al. (2019) concluded that the hygroscopicity of organic compounds is closely related to their individual polarity and highly polar compounds are usually more hygroscopic. Kier (1981) ranked the polarity of different functional groups in the sequence of $-\mathrm{CH} 3<-\mathrm{NH} 2<-\mathrm{OH}<-\mathrm{CHO}<-\mathrm{NH} 2 \mathrm{OH}<-\mathrm{COOH}$, which could explain the difference in the hygroscopicity of organics with various functionalities in our study.

Figure $4 \mathrm{~b}$ shows that the measured hygroscopicity of the straight-chain dicarboxylic acids alternate with the parity of the carbon numbers. It has to be noted that data of Glutaric acid (C5) is quoted from Chan et al. (2008). Bilde et al. (2003) observed an alternation in the volatility of dicarboxylic acids with the number of carbon atoms similar to the ones we observed for their hygroscopicity. They attributed this to the alternation in the molar enthalpies of fusion of those compounds. Moreover, we observed that some compounds (Xylitol vs. L-Arabitol and Fructose vs. Mannose) share the same molecular formular or functionality but vary differently in hygroscopicity as shown in Fig. 4c. Both findings suggest that other physico-chemical properties of organics besides molecular functionality may also contribute to the observed variation in their hygroscopicity. Previous studies (Petters et al., 2017; Marcolli and Peter, 2005) reported that the position of the functional groups could influence the hygroscopicity properties of organic compounds. For instance, Petters et al. (2017) suggested that organic molecules with the hydroperoxyl group close the end of carbon chain were more hygroscopic. Similarly, Fructose observed in our study, with the hydroxyl group in the tail of the carbon chain and being far away from the $\mathrm{C}=\mathrm{O}$ group, is more hygroscopic than Mannose of which these two groups are much closer to each other.

\subsection{2 $\kappa$ vs. water solubility and molar volume}

Previous studies suggested that for highly soluble compounds which are fully dissolved in the aqueous droplet, their hygroscopicity are mainly controlled by their molar volume $\left(M_{\text {org }} / \rho_{\text {org }}\right)$; while for slightly soluble compounds, their hygroscopicity is limited by their low water solubility (Petters et al., 2009; Kuwata et al., 2013; Nakao, 2017; Wang et al.,

205 2019). Hence, we considered two regimes in our study: (A) compounds that fully dissolved (highly soluble with solubility > $7 \times 10^{-1} \mathrm{~g} / \mathrm{ml}$ in this work or not saturated regime) and (B) compounds that are not fully dissolved (slightly soluble or saturated regime) in the aqueous droplets under $90 \%$ RH condition. In regime A, as shown in Fig. 5, the hygroscopicity decrease with increasing molar volume. Besides molar volume, the van't hoff factor (i), which accounts for the degree of dissociation of a compound in water, could also contribute to the overall hygroscopicity for fully dissolved compounds. Sugars, as non-

210 electrolytes with van't hoff factor of 1, do not dissociate in aqueous solutions (Giebl et al., 2002; Koehler et al., 2006; Rosenørn et al., 2006) and thus are less hygroscopic than the dicarboxylic acids which can dissociate in water and contribute to the reduction in water activity. Frosch et al. (2010) related the van't hoff factor with the pKa values for a series of carboxylic acids and found that the stronger the acid with smaller values of $\mathrm{pKa}$, the larger the van't hoff factor. This could explain why Maleic acid, even with a larger molar volume but a smaller pKa value (1.8) is more hygroscopic than Malonic acid (pKa = 2.4).

215 Organic compounds with low water solubility (regime B) could be obviously divided into two categories according to their hygroscopicity. One is non- or almost non-hygroscopic organics with $\kappa$ close or equal to 0 . These organics might present at solid or crystalline state and did not deliquesce at our measurement conditions during the whole RH range. Thus, their 
hygroscopicity is not only limited by their low water solubility but also their phase state and the energy that needed for the phase transition. With similar water solubility ranging from $\sim 1 \mathrm{e}^{-3}$ to $\sim 3 \mathrm{e}^{-1} \mathrm{~g} / \mathrm{ml}$ as the non-hygroscopic type, the other type of organics is moderate hygroscopic with $\kappa$ values larger than 0.1 . These organics with limited solubility may already partially deliquesce under our studied RH conditions (Chan et al., 2008; Hartz et al., 2006), and we found that their hygroscopic increase with water solubility. This is physically reasonable that the aqueous droplet of these organics with limited solubility can be considered as being composed of an effectively insoluble core with a saturated solution. The organic with higher water solubility would dissolve more in the saturated solution, which has a stronger 'solute effect', and thus contribute more to the water uptake and become more hygroscopic.

\subsection{3 к vs. O:C ratio}

Previous studies have suggested that the hygroscopicity parameter of organic species $\left(\kappa_{\text {org }}\right)$ is closely related with their O:C ratios (Jimenez et al., 2009; Chang et al., 2010; Lambe et al., 2011; Kuwata et al., 2013; Rickards et al., 2013; Cappa et al., 2011; Massoli et al., 2010). In this study, we plotted our measured $\kappa$ of the 23 organic compounds with their O:C ratios in Fig. 6 and for a wider atmospheric implication we compared them against previous results from different atmospheric environments (Mei et al., 2013; Wu et al., 2013; Hong et al., 2015; Wu et al., 2016; Hong et al., 2018; Deng et al., 2018; Kuang et al., 2020). Clearly, ambient organics show much lower O:C value as seen in Fig. 6. Ng et al. (2010) compiled the measured O:C data from different environments and concluded that at most sites, ambient organic aerosols mainly consist of oxygenated organic material (OOA) and hydrocarbon-like organic material (HOA). HOA, which arise from vehicle emissions, is the least oxidized with the average O:C value less than 0.2 (Xu et al., 2015; $\mathrm{Ng}$ et al., 2010; Xu et al., 2016; Li et al., 2020; Cao et al., 2019). Hence, with the inclusion of HOA in ambient aerosols, the average O:C value of the bulk organic is less than 1 , being generally lower than our laboratory-generated aerosols.

A general trend of the increase of $\kappa_{\text {org }}$ with increasing $\mathrm{O}: \mathrm{C}$ has also been observed for laboratory results but the correlation between $\kappa$ and $\mathrm{O}: \mathrm{C}$ falls into two categories. One is a non-hygroscopic organic group with a weak O:C-dependence as the blue shaded area in Fig. 6. We suggested these compounds with limited water solubility might not deliquesce yet under $90 \%$ RH as discussed previously. The other type shaded in red area in Fig. 6 is a moderate-hygroscopic group with a slightly stronger O:C-dependence. However, the correlation of both categories is not well, which may be effected from the other properties which discussed above. Compared to those laboratory-generated pure organic compounds, ambient organics are more complex, with divergent O:C-dependent hygroscopicity among different environments. For instance, the hygroscopicity of urban aerosols in Beijing was almost constant, being less sensitive to the variations of the organic oxidation level, which is similar as our non-hygroscopic organics (Wu et al., 2016). On the contrast, the suburban aerosols in central Germany (Wu et al., 2013) and in Guangzhou (Hong et al., 2018) exhibit a slightly stronger influence from their O:C ratio, being close to the behaviour (slope $\approx 0.12$ ) of the moderate hygroscopic organics with relative higher water solubilities in our study. As discussed in previous works (Rickards et al., 2013) some of the laboratory-generated pure organics share identical O:C ratio but differ widely in hygroscopicity. However, no molecular-specific information could be concluded further for those ambient organics. 
This on the other side indicates that great uncertainties may arise from the approximation of organic hygroscopicity based on their atomic O:C ratio for ambient aerosols. The use of a simplified average property (i.e., O:C ratio) to describe the hygroscopicity of ambient organics, whose constitute may be diverged considerably is quite risky. Additional measurements of other properties (e.g., functionality or water solubility) may be difficult due to both the highly complex mixture of ambient aerosols and technique limitations. However, laboratory-generated surrogate mixtures representing the complexity of ambient aerosols at least should be examined to test the variety in the relationship between the O:C ratio and $\kappa$.

\section{Atmospheric implication}

Our laboratory observations reveal that current thermodynamic models may not always accurately simulate the hygroscopic behavior of organic compounds, despite their previous success. Phase transition may occur during the hydration cycle, which are not reasonably considered in the thermodynamic models. This will lead to significantly biased predictions of organic hygroscopic behaviour, as can be seen in the case of the slightly soluble organics in our study. Moreover, the interactions between functional group and water molecules were previously believed to dominate particle hygroscopicity rather than the interactions between functional groups. However, we found that the group-group interaction may be also important in water uptake process. This effect is clearly revealed in our study by the discrepancy in the hygroscopicity of amino acids between measurements and model prediction. These limitations suggest that an improved mechanism with the inclusion of these processes (e.g., phase transition and intramolecular interactions) into these thermodynamic models is needed and require comprehensive data from empirical measurements to complement these models for validating predictions. Furthermore, extra care must be taken to deal with even more complex systems, such as multi-component mixtures with the presence of inorganic compounds in atmospheric particles.

270 In the previous section discussing the role of different physico-chemical properties of organics plays in aerosol hygroscopicity, the parameter $\kappa$ was converted by the measured GF under $90 \%$ RH. For those low or sparingly soluble organic compounds, the GF_derived $\kappa$ (also known as apparent $\kappa$ ) is RH-dependent (see Fig. S3 as an example) and cannot express their intrinsic $\kappa$ (expressed by fully dissolved compounds), when compounds are sufficiently soluble in water. As the RH increases, further dissolution of these organic compounds with promoted hygroscopicity is expected. In the real atmosphere, different $\mathrm{RH}$ conditions including both sub- and supersaturation can be reached. The measured GF or the apparent $\kappa$ of ambient aerosols at a certain RH may not be able to reveal their real hygroscopicity under various atmospheric conditions. Further calculations of other variables, for instance the liquid water content (LWC), surface area of wet particles and number concentration of CCN associated with the apparent $\kappa$ will be significantly biased. If possible, hygroscopicity measurements over large saturation range up to supersaturation, especially with the combination of $\mathrm{CCN}$ measurements provide an option to reduce the uncertainties, but requiring fast and stable scanning of RHs during the experiments. Technical improvement, for example in HTDMA system is essentially needed. 
https://doi.org/10.5194/acp-2021-486

Preprint. Discussion started: 30 June 2021

(c) Author(s) 2021. CC BY 4.0 License.

(c) (i)

\section{Data availability.}

The details data can be obtained from the corresponding author upon request.

\section{Supplement.}

285 The Principle of HTDMA system, calibration of instrument by using ammonium sulfate, calculations for E-AIM and UManSysProp models, hygroscopicity parameter $\kappa$ as a function of RH for sparingly soluble organics.

\section{Author contributions.}

SH contributed to investigation, data curation, visualization and writing original draft. JH and NM contributed to resources, writing review and editing. HBX contributed software, HBT, JCT, YQZ, LP, YH contributed to resources. QQW contributed to fund acquisition. JNS contributed to investigation. YFC, HS contributed to resources and fund acquisition.

\section{Competing interests.}

The authors declare no competing financial interest.

\section{Acknowledgments.}

This work was supported by the National Natural Science Foundation of China (No. 41705099 and 91644218), the National 295 Key Research and Development Program of China (Grant 2017YFC0210104), and Guangdong Innovative and Entrepreneurial Research Team Program (2016ZT06N263). 


\section{References}

Bilde, M., Svenningsson, B., Mønster, J., and Rosenørn, T.: Even- odd alternation of evaporation rates and vapor pressures of

C3- C9 dicarboxylic acid aerosols, Environ. Sci. Technol., 37, 1371-1378, https://doi.org/10.1021/es0201810, 2003.

Cao, L.-M., Huang, X.-F., Wang, C., Zhu, Q., and He, L.-Y.: Characterization of submicron aerosol volatility in the regional atmosphere in southern China, Chemosphere, 236, 124383, https://doi.org/10.1016/j.chemosphere.2019.124383, 2019.

Cappa, C. D., Che, D. L., Kessler, S. H., Kroll, J. H., and Wilson, K. R.: Variations in organic aerosol optical and hygroscopic properties upon heterogeneous OH oxidation, J.Geophy.Res.Atmos., 116, https://doi.org/10.1029/2011JD015918, 2011.

Chan, M. N., Kreidenweis, S. M., and Chan, C. K.: Measurements of the hygroscopic and deliquescence properties of organic compounds of different solubilities in water and their relationship with cloud condensation nuclei activities, Environ. Sci. Technol., 42, 3602-3608, https://doi.org/10.1021/es7023252, 2008.

Chan, M. N., Choi, M. Y., Ng, N. L., and Chan, C. K.: Hygroscopicity of water-soluble organic compounds in atmospheric aerosols: Amino acids and biomass burning derived organic species, Environ. Sci. Technol., 39, 1555-1562, https://doi.org/10.1021/es0495841, 2005.

Chang, R.-W., Slowik, J., Shantz, N., Vlasenko, A., Liggio, J., Sjostedt, S., Leaitch, W., and Abbatt, J.: The hygroscopicity parameter $(\kappa)$ of ambient organic aerosol at a field site subject to biogenic and anthropogenic influences: relationship to degree of aerosol oxidation, Atmos.Chem.Phys., 10, 5047-5064, https://doi.org/10.5194/acp-10-5047-2010, 2010.

Chebbi, A. and Carlier, P.: Carboxylic acids in the troposphere, occurrence, sources, and sinks: A review, Atmos. Environ.,

30, 4233-4249, https://doi.org/10.1016/1352-2310(96)00102-1, 1996.

Chen, J., Lee, W.-C., Itoh, M., and Kuwata, M.: A significant portion of water-soluble organic matter in fresh biomass burning particles does not contribute to hygroscopic growth: an application of polarity segregation by 1-Octanol-water partitioning method, Environ. Sci. Technol., 53, 10034-10042, https://doi.org/10.1021/acs.est.9b01696, 2019.

Cheng, Y., Wiedensohler, A., Eichler, H., Heintzenberg, J., Tesche, M., Ansmann, A., Wendisch, M., Su, H., Althausen, D., and Herrmann, H.: Relative humidity dependence of aerosol optical properties and direct radiative forcing in the surface boundary layer at Xinken in Pearl River Delta of China: An observation based numerical study, Atmos. Environ., 42, 63736397, https://doi.org/10.1016/j.atmosenv.2008.04.009, 2008.

Clegg, S. L., Brimblecombe, P., and Wexler, A. S.: Thermodynamic model of the system $\mathrm{H}^{+-} \mathrm{NH} 4+-\mathrm{Na}+-\mathrm{SO} 42--\mathrm{NO} 3--$ Cl-- H2O at 298.15 K, J. Phys. Chem. A, 102, 2155-2171, https://doi.org/10.1021/jp973043j, 1998.

Darr, J. P., Gottuso, S., Alfarra, M., Birge, D., Ferris, K., Woods, D., Morales, P., Grove, M., Mitts, W. K., and MendozaLopez, E.: The Hydropathy Scale as a Gauge of Hygroscopicity in Sub-Micron Sodium Chloride-Amino Acid Aerosols, J. Phys. Chem. A, 122, 8062-8070, https://doi.org/10.1021/acs.jpca.8b07119, 2018.

Deng, Y., Kagami, S., Ogawa, S., Kawana, K., Nakayama, T., Kubodera, R., Adachi, K., Hussein, T., Miyazaki, Y., and Mochida, M.: Hygroscopicity of Organic Aerosols and Their Contributions to CCN Concentrations Over a Midlatitude Forest in Japan, J.Geophy.Res.Atmos., 123, 9703-9723, https://doi.org/10.1029/2017JD027292, 2018. 
Estillore, A. D., Morris, H. S., Or, V. W., Lee, H. D., Alves, M. R., Marciano, M. A., Laskina, O., Qin, Z., Tivanski, A. V., and Grassian, V. H.: Linking hygroscopicity and the surface microstructure of model inorganic salts, simple and complex carbohydrates, and authentic sea spray aerosol particles, PCCP, 19, 21101-21111, DOI:10.1039/C7CP04051B, 2017.

Fredenslund, A., Jones, R. L., and Prausnitz, J. M.: Group-contribution estimation of activity coefficients in nonideal liquid mixtures, AlChE J., 21, 1086-1099, https://doi.org/10.1002/aic.690210607, 1975.

Frosch, M., Zardini, A. A., Platt, S., Müller, L., Reinnig, M.-C., Hoffmann, T., and Bilde, M.: Thermodynamic properties and cloud droplet activation of a series of oxo-acids, Atmospheric Chemistry \& Physics Discussions, 10, https://doi.org/10.5194/acp-10-5873-2010, 2010.

Giebl, H., Berner, A., Reischl, G., Puxbaum, H., Kasper-Giebl, A., and Hitzenberger, R.: CCN activation of oxalic and malonic

340 acid test aerosols with the University of Vienna cloud condensation nuclei counter, J. Aerosol Sci, 33, 1623-1634, https://doi.org/10.1016/S0021-8502(02)00115-5, 2002.

Hansen, H. K., Rasmussen, P., Fredenslund, A., Schiller, M., and Gmehling, J.: Vapor-liquid equilibria by UNIFAC group contribution. 5. Revision and extension, Industrial \& Engineering Chemistry Research, 30, 2352-2355, https://doi.org/10.1021/ie00058a017, 1991.

345 Hartz, K. E. H., Tischuk, J. E., Chan, M. N., Chan, C. K., Donahue, N. M., and Pandis, S. N.: Cloud condensation nuclei activation of limited solubility organic aerosol, Atmos. Environ., 40, 605-617, https://doi.org/10.1016/j.atmosenv.2005.09.076, 2006.

Hong, J., Kim, J., Nieminen, T., Duplissy, J., Ehn, M., Äijälä, M., Hao, L., Nie, W., Sarnela, N., and Prisle, N.: Relating the hygroscopic properties of submicron aerosol to both gas-and particle-phase chemical composition in a boreal forest environment, Atmos.Chem.Phys., 15, 11999-12009, https://doi.org/10.5194/acp-15-11999-2015, 2015.

Hong, J., Xu, H., Tan, H., Yin, C., Hao, L., Li, F., Cai, M., Deng, X., Wang, N., and Su, H.: Mixing state and particle hygroscopicity of organic-dominated aerosols over the Pearl River Delta region in China, Atmos.Chem.Phys., 18, 1407914094, https://doi.org/10.5194/acp-18-14079-2018, 2018.

Jimenez, J. L., Canagaratna, M., Donahue, N., Prevot, A., Zhang, Q., Kroll, J. H., DeCarlo, P. F., Allan, J. D., Coe, H., and $355 \mathrm{Ng}$, N.: Evolution of organic aerosols in the atmosphere, Science, 326, 1525-1529, DOI: 10.1126/science.1180353, 2009. Jing, B., Tong, S., Liu, Q., Li, K., Wang, W., Zhang, Y., and Ge, M.: Hygroscopic behavior of multicomponent organic aerosols and their internal mixtures with ammonium sulfate, Atmos.Chem.Phys., 16, 4101-4118, https://doi.org/10.5194/acp-16-41012016, 2016.

Kier, L. B.: Quantitation of solvent polarity based on molecular structure, J. Pharm. Sci., 70, 930-933, 360 https://doi.org/10.1002/jps.2600700825, 1981.

Koehler, K., Kreidenweis, S., DeMott, P., Prenni, A., Carrico, C., Ervens, B., and Feingold, G.: Water activity and activation diameters from hygroscopicity data-Part II: Application to organic species, Atmos.Chem.Phys., 6, 795-809, https://doi.org/10.5194/acp-6-795-2006, 2006. 
Kuang, Y., Xu, W., Tao, J., Ma, N., Zhao, C., and Shao, M.: A Review on Laboratory Studies and Field Measurements of Atmospheric Organic Aerosol Hygroscopicity and Its Parameterization Based on Oxidation Levels, Curr. Pollut. Rep., 6, 410424, https://doi.org/10.1007/s40726-020-00164-2, 2020.

Kundu, S., Kawamura, K., Andreae, T., Hoffer, A., and Andreae, M.: Molecular distributions of dicarboxylic acids, ketocarboxylic acids and $\alpha$-dicarbonyls in biomass burning aerosols: implications for photochemical production and degradation in smoke layers, Atmos.Chem.Phys., 10, 2209-2225, https://doi.org/10.5194/acp-10-2209-2010, 2010.

Kuwata, M., Shao, W., Lebouteiller, R., and Martin, S.: Classifying organic materials by oxygen-to-carbon elemental ratio to predict the activation regime of Cloud Condensation Nuclei (CCN), Atmos.Chem.Phys., 13, https://doi.org/10.5194/acp-135309-2013, 2013.

Lambe, A., Onasch, T., Massoli, P., Croasdale, D., Wright, J., Ahern, A., Williams, L., Worsnop, D., Brune, W. H., and Davidovits, P.: Laboratory studies of the chemical composition and cloud condensation nuclei (CCN) activity of secondary organic aerosol (SOA) and oxidized primary organic aerosol (OPOA), Atmos.Chem.Phys., 11, https://doi.org/10.5194/acp11-8913-2011, 2011.

Lei, T., Zuend, A., Wang, W., Zhang, Y., and Ge, M.: Hygroscopicity of organic compounds from biomass burning and their influence on the water uptake of mixed organic ammonium sulfate aerosols, Atmos. Chem. Phys, 14, 11165-11183, https://doi.org/10.5194/acp-14-11165-2014, 2014.

380 Lei, T., Zuend, A., Cheng, Y., Su, H., Wang, W., and Ge, M.: Hygroscopicity of organic surrogate compounds from biomass burning and their effect on the efflorescence of ammonium sulfate in mixed aerosol particles, Atmos.Chem.Phys., 18, 1045, https://doi.org/10.5194/acp-18-1045-2018, 2018.

Li, J., Liu, Z., Gao, W., Tang, G., Hu, B., Ma, Z., and Wang, Y.: Insight into the formation and evolution of secondary organic aerosol in the megacity of Beijing, China, Atmos. Environ., 220, 117070, https://doi.org/10.1016/j.atmosenv.2019.117070, 3852020.

Luo, Q., Hong, J., Xu, H., Han, S., Tan, H., Wang, Q., Tao, J., Ma, N., Cheng, Y., and Su, H.: Hygroscopicity of amino acids and their effect on the water uptake of ammonium sulfate in the mixed aerosol particles, Sci. Total Environ., 139318, https://doi.org/10.1016/j.scitotenv.2020.139318, 2020.

Marcolli, C. and Peter, T.: Water activity in polyol/water systems: new UNIFAC parameterization, 5, 1545-1555, 390 https://doi.org/10.5194/acp-5-1545-2005, 2005.

Marsh, A., Miles, R. E., Rovelli, G., Cowling, A. G., Nandy, L., Dutcher, C. S., and Reid, J. P.: Influence of organic compound functionality on aerosol hygroscopicity: dicarboxylic acids, alkyl-substituents, sugars and amino acids, Atmos.Chem.Phys., 17, 5583, https://doi.org/10.5194/acp-17-5583-2017, 2017.

Martău, G. A., Coman, V., and Vodnar, D. C.: Recent advances in the biotechnological production of erythritol and mannitol, 395 Crit. Rev. Biotechnol., 1-15, https://doi.org/10.1080/07388551.2020.1751057, 2020. 
Massoli, P., Lambe, A., Ahern, A., Williams, L., Ehn, M., Mikkilä, J., Canagaratna, M., Brune, W., Onasch, T., and Jayne, J.: Relationship between aerosol oxidation level and hygroscopic properties of laboratory generated secondary organic aerosol (SOA) particles, Geophys. Res. Lett., 37, https://doi.org/10.1029/2010GL045258, 2010.

McFiggans, G., Artaxo, P., Baltensperger, U., Coe, H., Facchini, M. C., Feingold, G., Fuzzi, S., Gysel, M., Laaksonen, A., and

Lohmann, U.: The effect of physical and chemical aerosol properties on warm cloud droplet activation, Atmos.Chem.Phys., 6, 2593-2649, https://doi.org/10.5194/acp-6-2593-2006, 2006.

Mei, F., Hayes, P. L., Ortega, A., Taylor, J. W., Allan, J. D., Gilman, J., Kuster, W., de Gouw, J., Jimenez, J. L., and Wang, J.: Droplet activation properties of organic aerosols observed at an urban site during CalNex-LA, J.Geophy.Res.Atmos., 118, 2903-2917, https://doi.org/10.1002/jgrd.50285, 2013.

405 Mikhailov, E., Vlasenko, S., Niessner, R., and Pöschl, U.: Interaction of aerosol particles composed of protein and saltswith water vapor: hygroscopic growth and microstructural rearrangement, Atmos. Chem. Phys., 4, 323-350, https://doi.org/10.5194/acp-4-323-2004, 2004.

Mikhailov, E., Vlasenko, S., Martin, S., Koop, T., and Pöschl, U.: Amorphous and crystalline aerosol particles interacting with water vapor: conceptual framework and experimental evidence for restructuring, phase transitions and kinetic limitations, Atmos.Chem.Phys., 9, 9491-9522, https://doi.org/10.5194/acp-9-9491-2009, 2009.

Mochida, M., Kawabata, A., Kawamura, K., Hatsushika, H., and Yamazaki, K.: Seasonal variation and origins of dicarboxylic acids in the marine atmosphere over the western North Pacific, J.Geophy.Res.Atmos., 108, https://doi.org/10.1029/2002JD002355,2003.

Nakao, S.: Why would apparent $\kappa$ linearly change with $\mathrm{O} / \mathrm{C}$ ? Assessing the role of volatility, solubility, and surface activity of 415 organic aerosols, Aerosol Sci. Technol., 51, 1377-1388, https://doi.org/10.1080/02786826.2017.1352082, 2017. Ng, N., Canagaratna, M., Zhang, Q., Jimenez, J., Tian, J., Ulbrich, I., Kroll, J., Docherty, K., Chhabra, P., and Bahreini, R.: Organic aerosol components observed in Northern Hemispheric datasets from Aerosol Mass Spectrometry, Atmos.Chem.Phys., 10, 4625-4641, https://doi.org/10.5194/acp-10-4625-2010, 2010.

Ohrem, H. L., Schornick, E., Kalivoda, A., and Ognibene, R.: Why is mannitol becoming more and more popular as a pharmaceutical excipient in solid dosage forms?, Pharm. Dev. Technol., 19, 257-262, https://doi.org/10.3109/10837450.2013.775154, 2014.

Peng, C., Chan, M. N., and Chan, C. K.: The hygroscopic properties of dicarboxylic and multifunctional acids: Measurements and UNIFAC predictions, Environ. Sci. Technol., 35, 4495-4501, https://doi.org/10.1021/es0107531, 2001.

Petters, M. and Kreidenweis, S.: A single parameter representation of hygroscopic growth and cloud condensation nucleus activity, https://doi.org/10.5194/acp-7-1961-2007, 2007.

Petters, M., Kreidenweis, S., Prenni, A., Sullivan, R., Carrico, C., Koehler, K. A., and Ziemann, P.: Role of molecular size in cloud droplet activation, Geophys. Res. Lett., 36, https://doi.org/10.1029/2009GL040131, 2009. 
Petters, S. S., Pagonis, D., Claflin, M. S., Levin, E. J., Petters, M. D., Ziemann, P. J., and Kreidenweis, S. M.: Hygroscopicity of organic compounds as a function of carbon chain length and carboxyl, hydroperoxy, and carbonyl functional groups, J. Phys. Chem. A, 121, 5164-5174, https://doi.org/10.1021/acs.jpca.7b04114, 2017.

Prenni, A. J., Petters, M. D., Kreidenweis, S. M., DeMott, P. J., and Ziemann, P. J.: Cloud droplet activation of secondary organic aerosol, J.Geophy.Res.Atmos., 112, https://doi.org/10.1029/2006JD007963, 2007.

Prenni, A. J., DeMott, P. J., Kreidenweis, S. M., Sherman, D. E., Russell, L. M., and Ming, Y.: The effects of low molecular weight dicarboxylic acids on cloud formation, J. Phys. Chem. A, 105, 11240-11248, https://doi.org/10.1021/jp012427d, 2001. Randall, D. A., Wood, R. A., Bony, S., Colman, R., Fichefet, T., Fyfe, J., Kattsov, V., Pitman, A., Shukla, J., and Srinivasan, J.: Climate models and their evaluation, in: Climate change 2007: The physical science basis. Contribution of Working Group I to the Fourth Assessment Report of the IPCC (FAR), Cambridge University Press, 589-662, 2007.

Rickards, A. M., Miles, R. E., Davies, J. F., Marshall, F. H., and Reid, J. P.: Measurements of the sensitivity of aerosol hygroscopicity and the $\kappa$ parameter to the $\mathrm{O} / \mathrm{C}$ ratio, J. Phys. Chem. A, 117, 14120-14131, https://doi.org/10.1021/jp407991n, 2013.

Rosenørn, T., Kiss, G., and Bilde, M.: Cloud droplet activation of saccharides and levoglucosan particles, Atmos. Environ., 40, 1794-1802, https://doi.org/10.1016/j.atmosenv.2005.11.024, 2006.

Su, H., Rose, D., Cheng, Y., Gunthe, S., Massling, A., Stock, M., Wiedensohler, A., Andreae, M., and Pöschl, U.: Hygroscopicity distribution concept for measurement data analysis and modeling of aerosol particle mixing state with regard to hygroscopic growth and CCN activation, Atmos.Chem.Phys., 10, 7489-7503, https://doi.org/10.5194/acp-10-7489-2010, 2010.

Suda, S. R. and Petters, M. D.: Accurate determination of aerosol activity coefficients at relative humidities up to $99 \%$ using the hygroscopicity tandem differential mobility analyzer technique, Aerosol Sci. Technol., 47, 991-1000, https://doi.org/10.1080/02786826.2013.807906, 2013.

450 Suda, S. R., Petters, M., Matsunaga, A., Sullivan, R., Ziemann, P., and Kreidenweis, S.: Hygroscopicity frequency distributions of secondary organic aerosols, J.Geophy.Res.Atmos., 117, https://doi.org/10.1029/2011JD016823, 2012.

Suda, S. R., Petters, M. D., Yeh, G. K., Strollo, C., Matsunaga, A., Faulhaber, A., Ziemann, P. J., Prenni, A. J., Carrico, C. M., and Sullivan, R. C.: Influence of functional groups on organic aerosol cloud condensation nucleus activity, Environ. Sci. Technol., 48, 10182-10190, https://doi.org/10.1021/es502147y, 2014.

455 Tan, H. B., Xu, H. B., Wan, Q. L., Li, F., Deng, X. J., Chan, P. W., Xia, D., and Yin, Y.: Design and Application of an Unattended Multifunctional H-TDMA System, Journal of Atmospheric and Oceanic Technology, 30, 1136-1148, 10.1175/Jtech-D-12-00129.1, https://doi.org/10.1175/JTECH-D-12-00129.1, 2013.

Tang, M., Chan, C. K., Li, Y. J., Su, H., Ma, Q., Wu, Z., Zhang, G., Wang, Z., Ge, M., and Hu, M.: A review of experimental techniques for aerosol hygroscopicity studies, Atmos.Chem.Phys., 19, 12631-12686, https://doi.org/10.5194/acp-19-12631$2019,2019$. 
Topping, D., Barley, M., Bane, M. K., Higham, N., Aumont, B., Dingle, N., and McFiggans, G.: UManSysProp v1. 0: an online and open-source facility for molecular property prediction and atmospheric aerosol calculations, Geoscientific Model Development, 9, 899-914, https://doi.org/10.5194/gmd-9-899-2016, 2016.

Wang, J., Shilling, J. E., Liu, J., Zelenyuk, A., Bell, D. M., Petters, M. D., Thalman, R., Mei, F., Zaveri, R. A., and Zheng, G.: Cloud droplet activation of secondary organic aerosol is mainly controlled by molecular weight, not water solubility, Atmos.Chem.Phys., 19, 941-954, https://doi.org/10.5194/acp-19-941-2019, 2019.

Wang, Z., Jing, B., Shi, X., Tong, S., Wang, W., and Ge, M.: Importance of water-soluble organic acid on the hygroscopicity of nitrate, Atmos. Environ., 190, 65-73, https://doi.org/10.1016/j.atmosenv.2018.07.010, 2018.

Wang, Z., Su, H., Wang, X., Ma, N., Wiedensohler, A., Pöschl, U., and Cheng, Y.: Scanning supersaturation condensation particle counter applied as a nano-CCN counter for size-resolved analysis of the hygroscopicity and chemical composition of nanoparticles, Atmospheric Measurement Techniques, 8, 2161-2172, https://doi.org/10.5194/amt-8-2161-2015, 2015.

Wexler, A. S.: Atmospheric aerosol models for systems including the ions $\mathrm{H}+, \mathrm{NH} 4+, \mathrm{Na}+, \mathrm{SO}_{2}-\mathrm{NO}^{-}-\mathrm{Cl}^{-}, \mathrm{Br}^{-}$, and H2O, J. Geophys. Res., 107, https://doi.org/10.1029/2001JD000451, 2002.

Wise, M. E., Surratt, J. D., Curtis, D. B., Shilling, J. E., and Tolbert, M. A.: Hygroscopic growth of ammonium 475 sulfate/dicarboxylic acids, J.Geophy.Res.Atmos., 108, https://doi.org/10.1029/2003JD003775, 2003.

Wu, Z., Zheng, J., Shang, D., Du, Z., Wu, Y., Zeng, L., Wiedensohler, A., and Hu, M.: Particle hygroscopicity and its link to chemical composition in the urban atmosphere of Beijing, China, during summertime, Atmos.Chem.Phys., 16, 1123-1138, https://doi.org/10.5194/acp-16-1123-2016, 2016.

Wu, Z., Poulain, L., Henning, S., Dieckmann, K., Birmili, W., Merkel, M., Pinxteren, D. v., Spindler, G., Müller, K., and

480 Stratmann, F.: Relating particle hygroscopicity and CCN activity to chemical composition during the HCCT-2010 field campaign, Atmos.Chem.Phys., 13, 7983-7996, https://doi.org/10.5194/acp-13-7983-2013, 2013.

Xu, J., Shi, J., Zhang, Q., Ge, X., Canonaco, F., Prévôt, A. S., Vonwiller, M., Szidat, S., Ge, J., and Ma, J.: Wintertime organic and inorganic aerosols in Lanzhou, China: sources, processes, and comparison with the results during summer, Atmos.Chem.Phys., 16, 14937-14957, https://doi.org/10.5194/acp-16-14937-2016, 2016.

485 Xu, L., Suresh, S., Guo, H., Weber, R. J., and Ng, N. L.: Aerosol characterization over the southeastern United States using high-resolution aerosol mass spectrometry: spatial and seasonal variation of aerosol composition and sources with a focus on organic nitrates, Atmos.Chem.Phys., 15, 7307-7336, https://doi.org/10.5194/acp-15-7307-2015, 2015.

Zhang, Q., Jimenez, J. L., Canagaratna, M., Allan, J. D., Coe, H., Ulbrich, I., Alfarra, M., Takami, A., Middlebrook, A., and Sun, Y.: Ubiquity and dominance of oxygenated species in organic aerosols in anthropogenically-influenced Northern 490 Hemisphere midlatitudes, Geophys. Res. Lett., 34, https://doi.org/10.1029/2007GL029979, 2007.

Zhang, R., Wang, G., Guo, S., Zamora, M. L., Ying, Q., Lin, Y., Wang, W., Hu, M., and Wang, Y.: Formation of urban fine particulate matter, Chem. Rev., 115, 3803-3855, https://doi.org/10.1021/acs.chemrev.5b00067, 2015. 
https://doi.org/10.5194/acp-2021-486

Preprint. Discussion started: 30 June 2021

(C) Author(s) 2021. CC BY 4.0 License.

(c) (i)

Zheng, G., Duan, F., Su, H., Ma, Y., Cheng, Y., Zheng, B., Zhang, Q., Huang, T., Kimoto, T., and Chang, D.: Exploring the severe winter haze in Beijing: the impact of synoptic weather, regional transport and heterogeneous reactions, 495 Atmos.Chem.Phys., 15, 2969-2983, https://doi.org/10.5194/acp-15-2969-2015, 2015.

Zuend, A., Marcolli, C., Luo, B. P., and Peter, T.: A thermodynamic model of mixed organic-inorganic aerosols to predict activity coefficients, Atmos.Chem.Phys., 8, 4559-4593, https://doi.org/10.5194/acp-8-4559-2008, 2008.

Zuend, A., Marcolli, C., Booth, A., Lienhard, D. M., Soonsin, V., Krieger, U., Topping, D. O., McFiggans, G., Peter, T., and Seinfeld, J. H.: New and extended parameterization of the thermodynamic model AIOMFAC: calculation of activity

500 coefficients for organic-inorganic mixtures containing carboxyl, hydroxyl, carbonyl, ether, ester, alkenyl, alkyl, and aromatic functional groups, Atmos.Chem.Phys., 11, 9155-9206, https://doi.org/10.5194/acp-11-9155-2011, 2011. 
https://doi.org/10.5194/acp-2021-486

Preprint. Discussion started: 30 June 2021

(c) Author(s) 2021. CC BY 4.0 License.

Table 1. Substance and their relevant properties investigated in this study.

\begin{tabular}{|c|c|c|c|c|c|c|c|}
\hline Compounds & $\begin{array}{l}\text { Molecular } \\
\text { structure }\end{array}$ & $\begin{array}{l}\text { Chemical } \\
\text { formula }\end{array}$ & $\begin{array}{c}\text { Molar } \\
\text { weight } \\
\left(\mathrm{g} \mathrm{mol}^{-1}\right)\end{array}$ & $\begin{array}{l}\text { Density } \\
\left(\mathrm{g} \mathrm{cm}^{-3}\right)\end{array}$ & $\mathrm{O} / \mathrm{C}$ & $\begin{array}{l}\text { Solubility } \\
\left(\mathrm{g} \mathrm{ml}^{-1}\right)\end{array}$ & Supplier /purity \\
\hline $\begin{array}{c}\text { Ammonium } \\
\text { sulfate }\end{array}$ & $\begin{array}{l}\mathrm{NH}_{4}^{+} \|_{\mathrm{O}}^{\mathrm{O}}-\mathrm{NH}_{4}^{+}-\mathrm{O}^{-} \\
\mathrm{NH}^{+}\end{array}$ & $\left(\mathrm{NH}_{4}\right)_{2} \mathrm{SO}_{4}$ & $132.14^{\mathrm{a}}$ & $1.77^{\mathrm{a}}$ & - & $0.77^{\mathrm{a}}$ & Macklin, $99.99 \%$ \\
\hline
\end{tabular}

Sugars

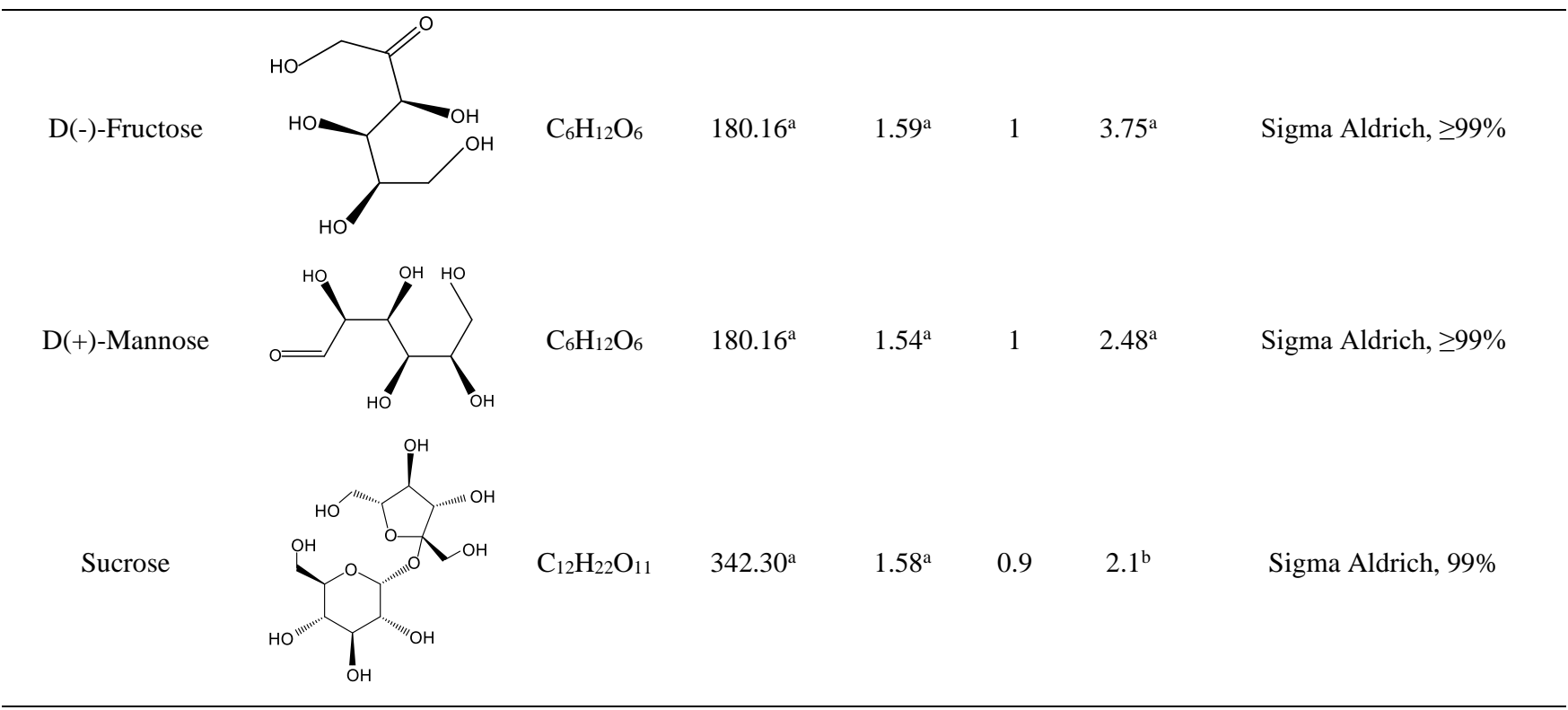

Sugar alcohols

L-(-)-Arabitol


Carboxylic acids

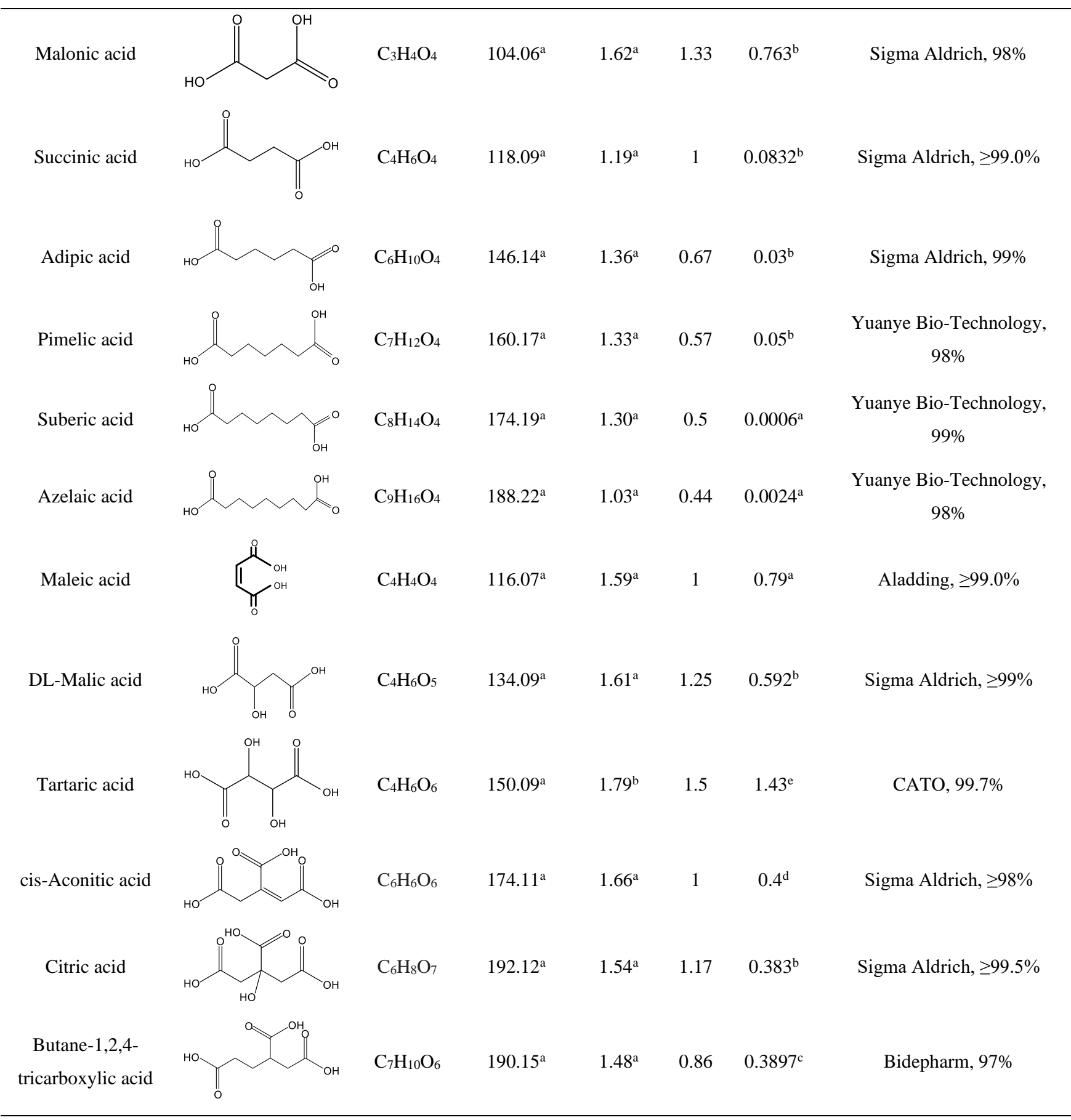


https://doi.org/10.5194/acp-2021-486

Preprint. Discussion started: 30 June 2021

(c) Author(s) 2021. CC BY 4.0 License.

(c) (1)

Atmospheric

Chemistry

and Physics

Discussions

L-Serine

${ }^{a}$ https://www.chemicalbook.com/ ${ }^{\mathrm{b}}$ https://pubchem.ncbi.nlm.nih.gov/ ${ }^{\mathrm{c}}$ https://www.chemspider.com/

$505{ }^{\mathrm{d}}$ https://hmdb.ca/ ${ }^{\mathrm{e}}$ Peng et al. (2001) 
(a)

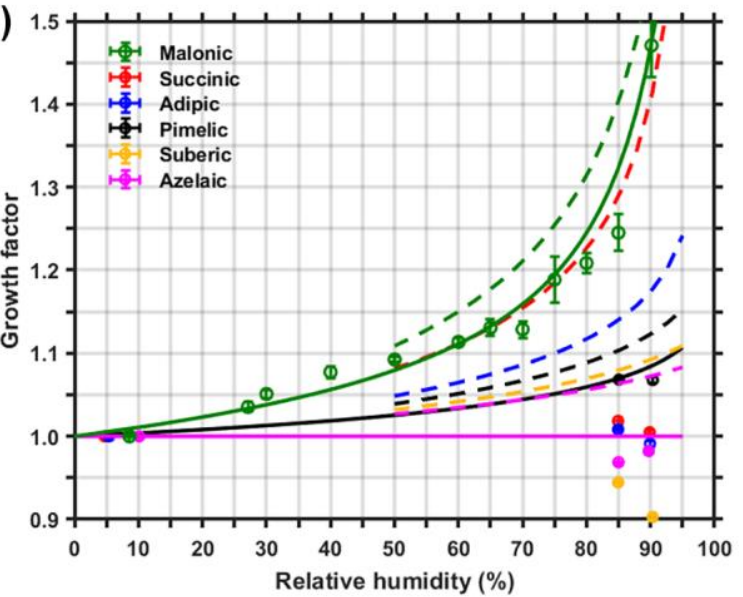

(b)

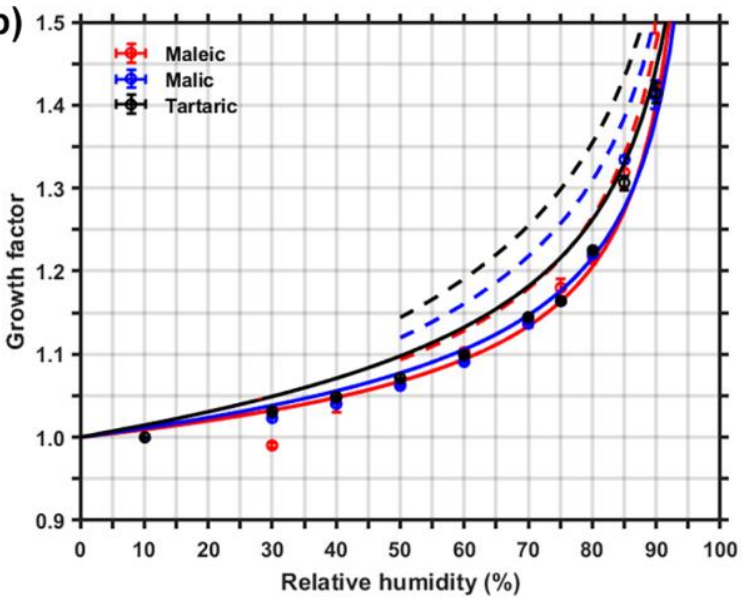

(c)

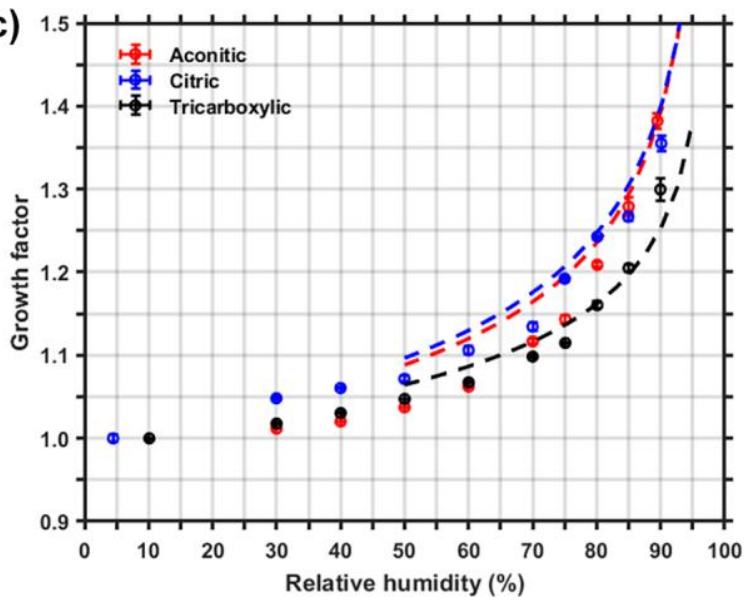

Figure 1. Hygroscopic growth curves of (a) and (b) dicarboxylic acids, (c) tricarboxylic acids particles (200nm). Points represent the measurement data; the solid lines indicate the E-AIM predictions (solid, non-hygroscopic organic $G F=1$ ) and the dashed lines show the UManSysProp calculated predictions. 
https://doi.org/10.5194/acp-2021-486

Preprint. Discussion started: 30 June 2021

(c) Author(s) 2021. CC BY 4.0 License.

(c) (i)

\begin{tabular}{l} 
Atmospheric \\
Chemistry \\
and Physics \\
\hline Discussions
\end{tabular}

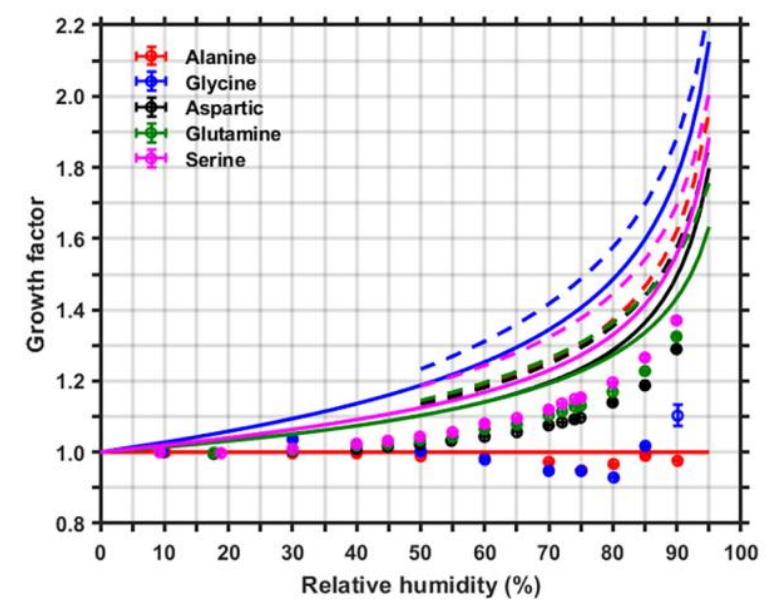

Figure 2. Hygroscopic growth factors of amino acids. The solid lines indicate the E-AIM predictions (solid, non-hygroscopic organic GF =1) and the dashed lines represent the UManSysProp calculated predictions. 
https://doi.org/10.5194/acp-2021-486

Preprint. Discussion started: 30 June 2021

(c) Author(s) 2021. CC BY 4.0 License.

(c) (i)

(a)

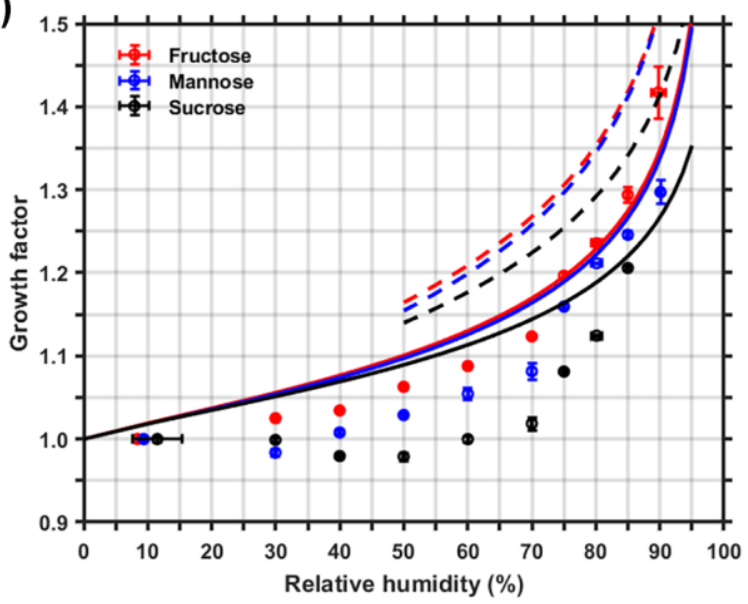

(b)

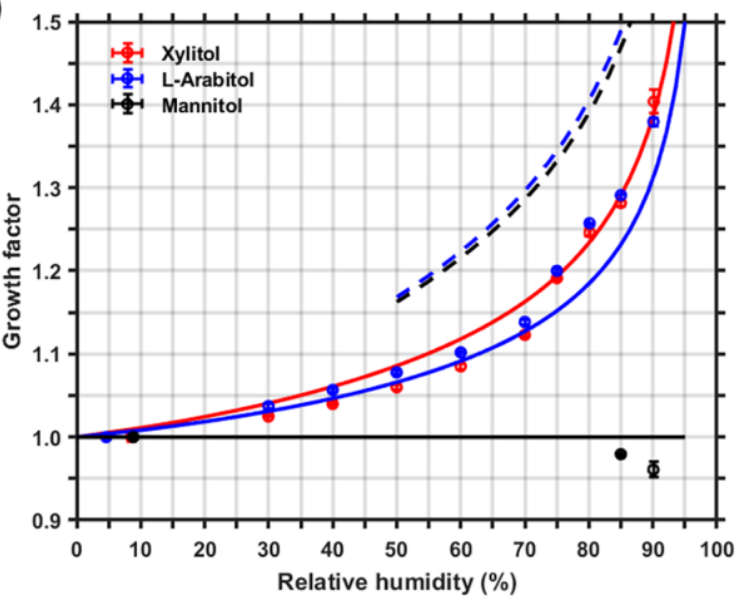

Figure 3. Hygroscopic growth curves of (a) sugars, (b) alcohols. Points represent the measurement values; the solid lines indicate the E-AIM predictions (solid, non-hygroscopic organic $\mathbf{G F = 1 )}$ and the dashed lines represent the UManSysProp calculated predictions. 

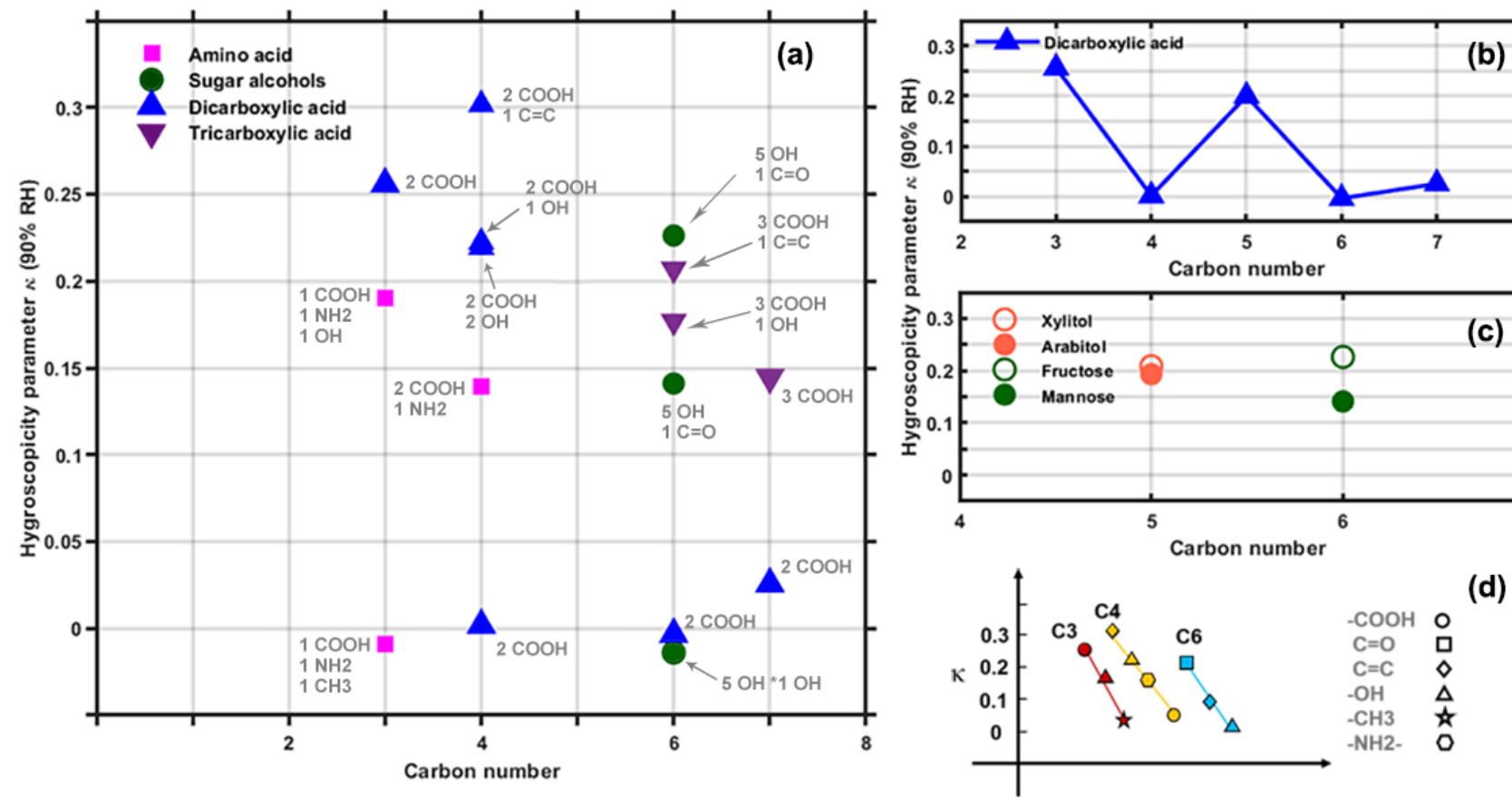

Figure 4. (a) Hygroscopicity of organics as a function of carbon number; (b) hygroscopicity of dicarboxylic acids vs carbon number; (c) hygroscopicity of isomers 
https://doi.org/10.5194/acp-2021-486

Preprint. Discussion started: 30 June 2021

(c) Author(s) 2021. CC BY 4.0 License.

(c) (i)

Atmospheric

Chemistry

and Physics

Discussions

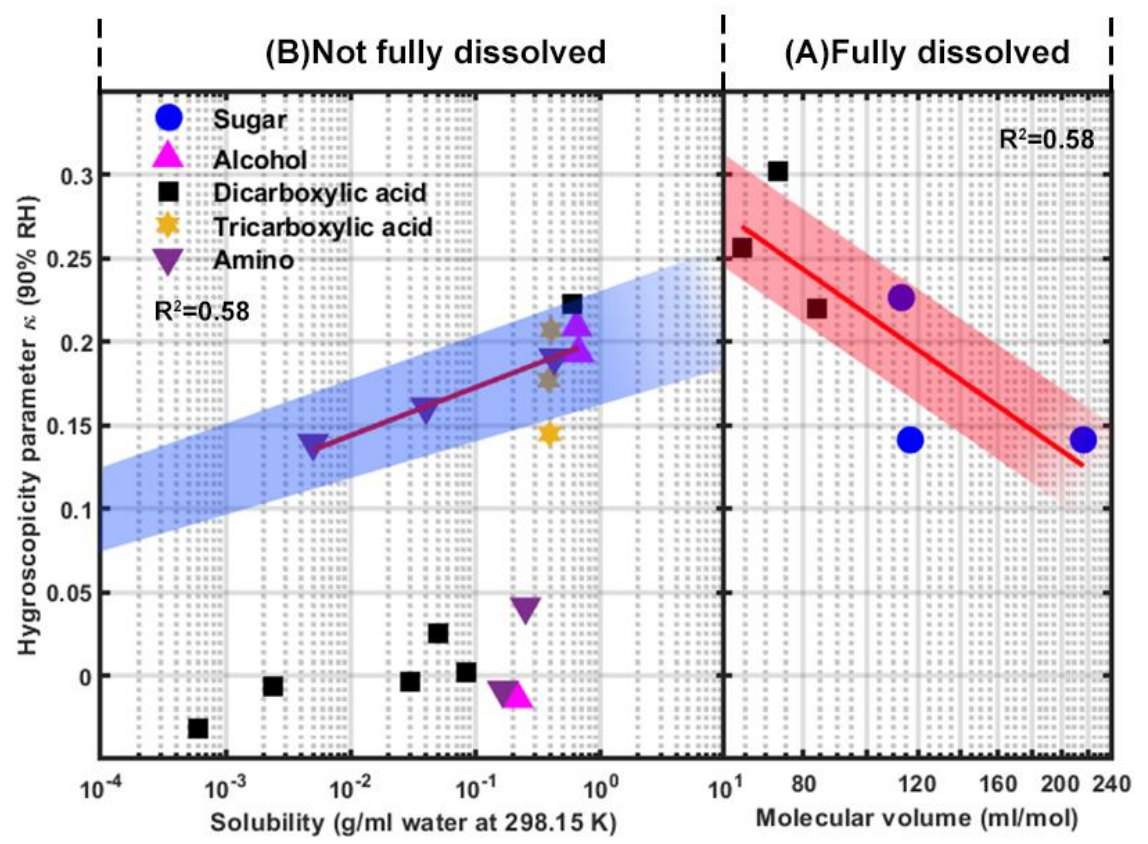

520 Figure 5. Hygroscopicity of organic compounds as a function of (A) molecular volume, (B) solubility. 
https://doi.org/10.5194/acp-2021-486

Preprint. Discussion started: 30 June 2021

(c) Author(s) 2021. CC BY 4.0 License.

(c) (i)

\begin{tabular}{l} 
Atmospheric \\
Chemistry \\
and Physics \\
\hline Discussions
\end{tabular}

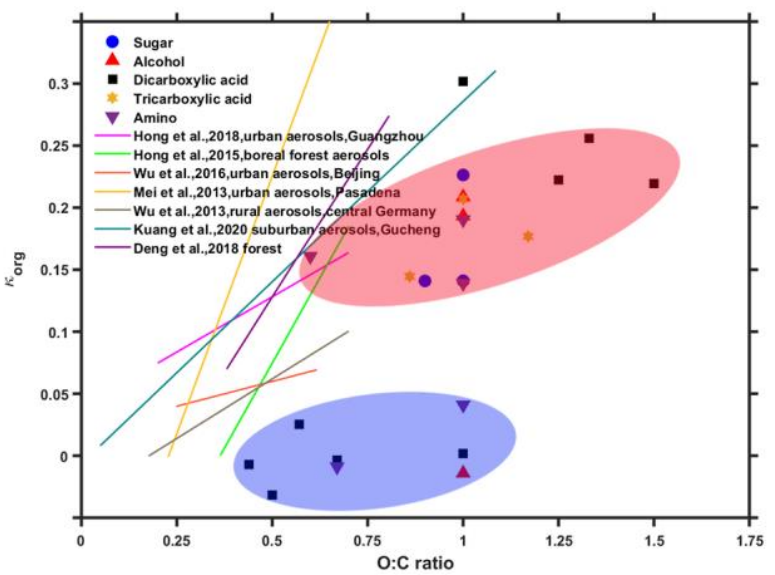

Figure 6. Correlation between $\mathrm{O}: \mathrm{C}$ ratio and $\kappa o r g$. Comparing previous literatures results with pure compounds measured in this study. Blue and red shades represent the fitting of non-hygroscopic and more hygroscopic organics, respectively. 